\title{
Genetic consequences of a bottleneck and spatial genetic structure in the triggerplant Stylidium coroniforme (Stylidiaceae)
}

\author{
DAVID J. COATES \\ Western Australian Herbarium, Department of Conservation and Land Management, P.O. Box 104, COMO Western \\ Australia 6152
}

\begin{abstract}
The genetic consequences of a bottleneck, and the spatial genetic structure within and between populations, were studied in the rare and geographically restricted species Stylidium coroniforme. Thirteen out of 15 allozyme loci analysed were polymorphic. The level of polymorphism was relatively high for an insect-pollinated outcrossing species. In one population, which was subjected to a prolonged decline in numbers resulting in a bottleneck, probably of three plants, there was no measurable reduction in either allelic diversity of average heterozygosity. Maintenance of heterozygosity in this population could be attributed to rapid recovery after the bottleneck, the progressive elimination of selfed or otherwise inbred products during seed development and selection favouring heterozygotes as plants mature. Evidence for the latter was a significant decrease in the fixation index from younger $(F=0.28)$ to older plants $(F=0.14)$. Bottleneck-flush cycles are considered to be a major factor contributing to the relatively high level of differentiation observed between the three Wongan Hills populations, which suggests that the bottleneck observed was not atypical for these populations. The allozyme divergence between the two population systems within this taxon $(D=0.29)$ may be indicative of two different but morphologically cryptic species. Spatial autocorrelation techniques revealed no spatial genetic structure in one population sampled at its maximum density. It was concluded that high levels of genetic diversity in small populations are typical of $S$. coroniforme, which is relatively short lived, disturbance-adapted and has population systems which probably undergo frequent bottleneck-flush cycles.
\end{abstract}

Keywords: bottleneck, differentiation, genetic variability, heterozygosity, spatial genetic structure, Stylidium coroniforme.

\section{Introduction}

Many perennial plant populations, even of relatively long lived species, can show dramatic fluctuations in numbers following environmental or habitat perturbations or rapid successional changes in the associated vegetation. In these situations, however, it is not clear whether such reductions in the number of individuals per population will result in a genetic bottleneck leading to reduced heterozygosity and genetic variability. In some species, such as Eucalyptus caesia (Moran \& Hopper, 1983), Eucalyptus pendens (Moran \& Hopper, 1987) and Acacia anomala (Coates, 1988), reduced population size does not necessarily lead to either a reduction in heterozygosity or a significant loss of genetic diversity. Similarly Echium plantagineum, a colonizing species introduced into Australia, shows unusually high levels of heterozygosity and allelic diversity even though it is likely to have gone through multiple bottlenecks on and since its introduction (Brown \& Burdon, 1983).

Contradictory evidence concerning the genetic consequences of small population size indicates that a range of factors need to be considered. Some of these have been addressed in theoretical models. For instance historical factors, such as the length of time the population has remained small and isolated, and the original population size, will be critical. Theoretical models indicate that, while rare alleles are likely to be lost, the reduction in average heterozygosity per locus will depend upon both the size of the bottleneck and the subsequent rate of population recovery (Nei et al., 1975; Chakraborty \& Nei, 1977). The bottleneck must be $<10$ individuals to reduce significantly the number 
of alleles per locus and even smaller to effect the average heterozygosity greatly.

Other factors, such as the breeding system, natural selection and demography will also be crucial in determining the genetic consequences of a demographic bottleneck in plant populations (Schwaegerle \& Schaal, 1979; Brown \& Burdon, 1983; McClenaghan \& Beauchamp, 1986). These have largely been ignored in founder effect models. For example, we know that the mating system plays an important role in influencing the amount of genetic variation and its organization (see Hamrick \& Godt, 1989). Many studies have shown that high levels of inbreeding in largely self pollinating species will result in reduced levels of heterozygosity and increased divergence between populations. Brown (1979), however, refers to a 'heterozygosity paradox' where there is a trend to greater heterozygosity than expected in inbreeding populations and less than expected in outbreeding populations. Although the reason for this paradox remains unclear, it has important implications for assessing the genetic consequences of reduced population size and population bottlenecks in species with different breeding systems. Furthermore, a number of studies have documented a relationship between increased fitness and heterozygosity (see Mitton, 1989). In particular, resistance to environmental stress may be associated with increased heterozygosity (Mopper et al., 1991). The consequence of such a relationship may be to maintain or even increase heterozygosity in a population following a substantial reduction in population size due to environmental perturbation.

Although it appears that in some cases a demographic bottleneck will not result in a loss of heterozygosity or allelic diversity, there seems little doubt that severe bottlenecks can cause rapid shifts in allele frequencies (see Johnson, 1988; Taggart et al., 1989). This may lead to changes at individual loci and to a concerted change in the genome which a number of authors have postulated is the key to rapid and recent speciation (White, 1978; Carson \& Templeton, 1984).

A further consequence of a bottleneck followed by a population flush, particularly in plant populations, could be a substantial change in spatial genetic structure. Changes in both population density and genetic structure would be expected to have a significant influence on the level of inbreeding (Ritland, 1986; Brown, 1989; Watkins \& Levin, 1990). Local genetic structure is considered to be a common feature of plant populations although evidence from gene flow (Schaal, 1980) and spatial autocorrelation studies (Waser, 1987; Dewey \& Heywood, 1988) suggests it may not be as common as once thought. Species characterized by population systems which typically go through a bottleneck followed by a population 'flush', might be expected to show genetic structure within populations but only at certain stages of cycle. Although there is a lack of empirical data on temporal changes in spatial genetic structure in plant populations, some preliminary predictions have been made based on the breeding system, seed dispersal patterns and selection regimes (see Hamrick, 1989).

Stylidium coroniforme is a rare and geographically restricted species known from only five populations. Like all perennial triggerplants it is protandrous and self compatible (Hopper, 1982; Burbidge \& James, 1991). Although insect-pollinated and outcrossing, geitogamous pollination and crossing between near neighbours is likely to lead to significant inbreeding within populations. In addition, like many other perennial triggerplants, it appears to be a disturbance opportunist with populations typically going through bottleneck-flush cycles in association with temporary habitat perturbations such as fire. This study was initiated to investigate the genetic consequences, both spatially and temporally, of a recent and prolonged demographic bottleneck in one of these populations, and the patterns of genetic diversity in an extremely disjunct population system.

\section{Materials and methods}

\section{Population sampling}

The five populations of $S$. coroniforme are found in the central cereal growing region of south-west Australia. Most of the native vegetation has been cleared for agriculture with some 7 per cent remaining as remnants of various sizes. S. coroniforme, like many other triggerplants, occurs in discrete populations in which numbers can fluctuate widely depending upon seasonal conditions and the level of disturbance. A similar population system is likely to have existed prior to land clearing although it is now far more dissected following the destruction of much of its habitat. Consequently this species is now found at only five locations (Table 1). Populations $(1,2$ and 3$)$ within $7 \mathrm{~km}$ of each other in the Wongan Hills and populations ( 3 and 4 ) within $2 \mathrm{~km}$ of each other, $140 \mathrm{~km}$ to the north (Fig. 1). Any intervening populations now appear to be extinct.

S. coroniforme was considered extinct until one plant was found (population 1) in 1980 (Rye, 1980; Hopper, 1982). In 1963 this population was estimated to have several hundred plants (Erickson \& Willis, 1966). Subsequently it suffered severely from habitat disturbance, grazing and drought. Following the discovery of a single plant the area was fenced and in 1981 a second mature plant was found, followed by a third in 
1982. By 1986 the population had increased to 84 plants (see Table 1). The initial increase in numbers in the population was probably due to plants regenerating from rootstock (Hopper, 1982) with subsequent recruitment from seed. By 1984 all new plants appeared to have been recruited from seed (J. O. Briggs

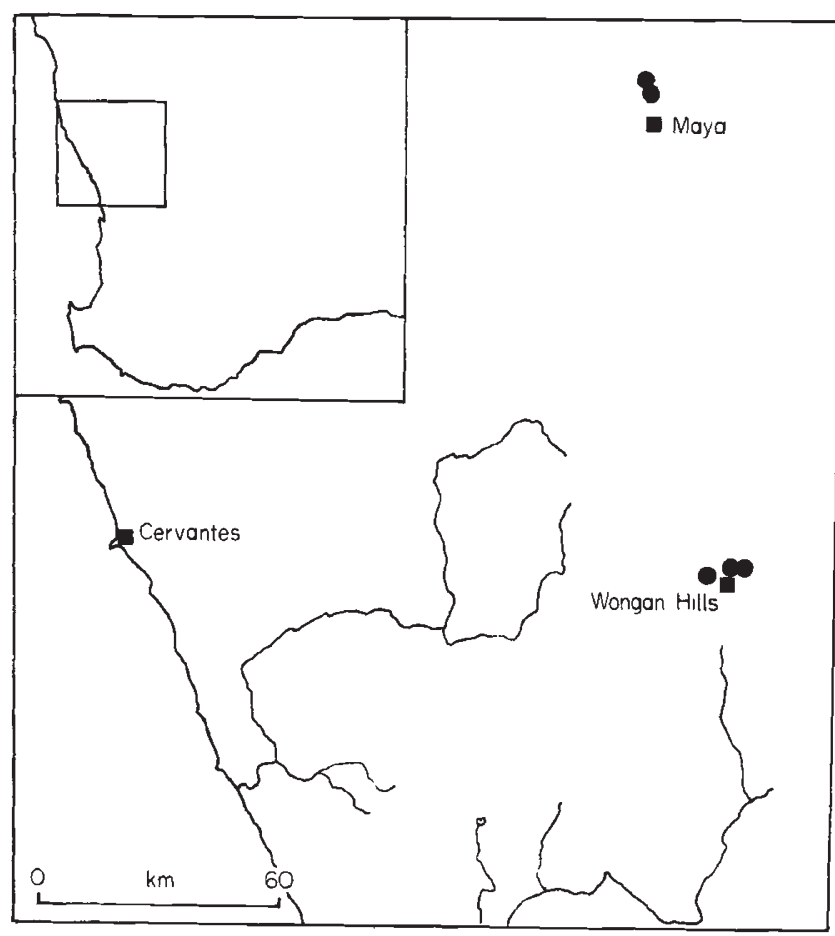

Fig. 1 Distribution of Stylidium coroniforme in south-west Australia. personal communication). Although thorough searching in 1980 located only one plant, evidence that the new plants detected in 1981 and 1982 regenerated from rootstock suggests that the original bottleneck size was probably three.

Unlike population 1 there is no evidence to suggest that the other populations had been subjected to a severe and prolonged bottleneck. However, all four remaining populations were found, partly or wholly, in areas which had been disturbed in the past 6 years and then left to regenerate. Because this species appears to require habitat disturbance (e.g. fire) for a temporary increase in population size, plant numbers in these populations are likely to be much higher than in completely undisturbed sites. Indeed in undisturbed areas associated with populations 2 and 3, thorough searching detected only a few plants at extremely low densities.

Anther material from old buds or recently opened flowers was found to be the most suitable for allozyme electrophoresis. Every plant in population 1 was sampled between 1986 and 1989, 50 plants were sampled from population 2, 60 from population 3 and all plants with suitable bud or flower material were sampled from populations 4 and 5. Actual population sizes at the time of sampling are shown in Table 1.

\section{Isozyme electrophoresis and data analysis}

Preparation of anther material and the isozyme methods, using the Helena Laboratory cellulose acetate plate electrophoresis system, were as described previously (Coates, 1988).

Table 1 Plant numbers for each of the populations of $S$. coroniforme. The initial plants observed in population 1 are likely to have come from both regenerating rootstocks and seed. From 1984 onwards all new recruitment was from seed

\begin{tabular}{lcc}
\hline Population & Year & Number of plants \\
\hline 1 Wongan Hills & 1963 & $>200$ (Erickson \& Willis, 1966) \\
& 1980 & 1 (Rye, 1980; Hopper, 1982) \\
& 1981 & 2 (Hopper, 1982) \\
& 1982 & 2 (P. Roberts personal communication) \\
& 1984 & 32 (P. Roberts personal communication) \\
& 1985 & 86 \\
& 1986 & 54 \\
& 1989 & 29 \\
2 Wongan Hills & 1991 & 150 \\
Wongan Hills & 1989 & 62 \\
Sub-population 1 & 1991 & 170 \\
Sub-population 2 & & 69 \\
Maya & 1989 & 42 \\
4 Maya & 1989 & \\
\hline
\end{tabular}


Nine enzyme systems were assayed: aspartate aminotransferase (AAT, E.C. 2.6.1.1), glucosephosphate isomerase (GPI, E.C. 5.3.1.9), glutamate dehydrogenase (GDH, E.C. 1.4.1.3), isocitrate dehydrogenase (IDH, E.C. 1.1.1.42), leucine aminopeptidase (LAP, E.C. 3.4.17.1), malate dehydrogenase (MDH, E.C. 1.1.1.37), menadione reductase (MDR, 1.6.99.22), 6 phosphogluconate dehydrogenase (6PGD, E.C. 1.1.1.44) and phosphoglucomutase (PGM, E.C. 2.7.5.1). A total of 15 zones of activity were scored and each zone was assumed to represent a single locus. Loci were designated numerically beginning with the most anodal zone. Alleles at each locus were designated alphabetically with the most anodel allele being ' $a$ ' and all others lettered in order of decreasing electrophoretic mobility. Only two loci, $I d h-1$ and $M d h-2$, were not polymorphic.

The average number of alleles per locus $(A)$, percentage polymorphic loci $(P)$, observed heterozygosity $\left(H_{\mathrm{O}}\right)$ expected heterozygosity $\left(H_{e}\right)$ and Wright's fixation index $(F)$ were calculated as described by Brown \& Weir (1983). The partitioning of genetic variation within and among populations and among the two disjunct population groups, Wongan Hills and Maya, was analysed by gene diversity measures described by $\mathrm{Nei}$ \& Chesser (1983). Nei's (1978) genetic distance $(D)$ was calculated for each pairwise combination of populations and a UPGMA phenogram constructed. The single locus diversity measures, $A, P, H_{\mathrm{e}}$ andd $H_{\mathrm{O}}, D, F$ and the UPGMA phenogram were determined using the computer program Bıosys-1 (Swofford \& Selander, 1989). The variance of $F$ was calculated as described by Brown \& Weir (1983) for a diallelic locus and where there were more than two alleles per locus, the frequencies of the rarer alleles were combined. Assuming the marker loci are statistically independent, the mean variance of $F$ per population was calculated as the mean of the separate variances divided by the number of loci (Brown \& Weir, 1983).

Two indirect estimates of gene flow $(\mathrm{Nm})$ were calculated between subpopulations, populations and between the two population groups. The first was based on the relationship $F_{\mathrm{ST}}=1 /[4 \mathrm{Nm}+1]$ (Wright, 1951) where $F_{\mathrm{ST}}$ was calculated as described by Weir \& Cochran (1984). The second was based on the frequency distributions of private alleles $p(l)$ (alleles found in only a single population) using the relationship:

$\log _{10}[p(l)]=a \log _{10}(N m)+b$

where $a$ and $b$ depend on the number of individuals sampled from each population (Slatkin, 1985; Slatkin \& Barton, 1989).

Spatial autocorrelation analysis was carried out in population 1 on individual allelic data at nine loci using the computer program AUTOCORR, developed by Heywood (see Dewey \& Heywood, 1988). Moran's I (Sokal \& Oden, 1978) was used to quantify spatial structuring of allozymes. Two methods of pairing individuals were used, based on the Gabriel connection algorithm and the nearest neighbour algorithim. These are considered to provide the most powerful tests for spatial structure (Dewey \& Heywood, 1988). The relationship between spatial structure and distance between individuals was also examined by calculating $I$ for all pairs of individuals within a specified distance class as a function of distance class (Sokal \& Oden, 1978, 1978; Dewey \& Heywood, 1988). These data can be visualized by constructing a correlogram of $I$ against distance class.

\section{Results}

\section{Genetic variation within populations}

Gene frequencies for the 13 polymorphic loci in the five populations of $S$. coroniforme are shown in Table 2 . There are clear allele frequency differences between populations at a number of loci, in particular Aat-2, Gpi-1, Gpi-2, Lap-1, 6pgd-1, 6pgd-2, and Pgm-1, with noticeable differentiation between the two population groups.

The single locus diversity measures (Table 3), especially the expected heterozygosity or genetic diversity index $\left(H_{\mathrm{e}}\right)$, indicate relatively high levels of genetic diversity for an animal-pollinated outcrossing species (see Hamrick \& Godt, 1989). The bottleneck in population 1 appears to have had little effect on either allelic diversity or average heterozygosity. Indeed, the observed heterozygosity was greater in population 1 than the larger populations, 2 and 3 . Furthermore, allelic diversity measured by $A, P$, and $H_{\mathrm{e}}$ was the same as observed in the largest population, population 3 , and greater than that observed in any of the other populations.

A comparison between older plants (4-9 years) and younger plants (1-4 years), within population 1 , shows that although $A, P$, and $H_{\mathrm{e}}$ are extremely similar, the observed heterozygosity $\left(H_{\mathrm{O}}\right)$ is higher and the average fixation index $(F)$ is significantly lower. That is, older plants are on average more heterozygous than younger plants. However, because plants were aged in terms of the number of rosettes, it is possible that plant size is also associated with the level of heterozygosity.

\section{Differentiation between populations and gene flow}

Gene diversity measures (Table 4 ) indicate that $S$. coroniforme has relatively high levels of genetic diversity $\left(H_{\mathrm{T}}=0.521\right)$ and substantial differentiation 
Table 2 Allele frequencies for the 13 polymorphic loci in the five populations of Stylidium coroniforme

\begin{tabular}{|c|c|c|c|c|c|c|}
\hline \multirow[b]{3}{*}{ Locus } & \multirow[b]{3}{*}{ Allele } & \multicolumn{5}{|c|}{ Populations } \\
\hline & & \multicolumn{3}{|c|}{ Wongan Hills } & \multicolumn{2}{|l|}{ Maya } \\
\hline & & 1 & 2 & 3 & 1 & 2 \\
\hline \multirow[t]{3}{*}{ Aat-1 } & A & 0.12 & 0.04 & 0.03 & 0.26 & 0 \\
\hline & B & 0.34 & 0.60 & 0.61 & 0.70 & 0.95 \\
\hline & $\mathrm{C}$ & 0.54 & 0.36 & 0.36 & 0.04 & 0.05 \\
\hline \multirow[t]{4}{*}{ Aat-2 } & A & 0.27 & 0.93 & 0.88 & 0.12 & 0.03 \\
\hline & B & 0.08 & 0.07 & 0.06 & 0.73 & 0.92 \\
\hline & $\mathrm{C}$ & 0.13 & 0 & 0.04 & 0.15 & 0.05 \\
\hline & $\mathrm{D}$ & 0.52 & 0 & 0.02 & 0 & 0 \\
\hline \multirow[t]{3}{*}{$G d h-1$} & A & 0.13 & 0.76 & 0.27 & 0 & 0 \\
\hline & B & 0.87 & 0.24 & 0.73 & 0.77 & 0.94 \\
\hline & $\mathrm{C}$ & 0 & 0 & 0 & 0.23 & 0.06 \\
\hline \multirow[t]{2}{*}{ Gpi-1 } & A & 0.43 & 0.13 & 0.64 & 0.66 & 0.84 \\
\hline & B & 0.57 & 0.87 & 0.36 & 0.34 & 0.16 \\
\hline \multirow[t]{4}{*}{ Gpl-2 } & A & 0.14 & 0.01 & 0.05 & 0.11 & 0.13 \\
\hline & B & 0.57 & 0.90 & 0.48 & 0.25 & 0.24 \\
\hline & C & 0.29 & 0.09 & 0.47 & 0.62 & 0.58 \\
\hline & $\mathrm{D}$ & 0 & 0 & 0 & 0.02 & 0.05 \\
\hline \multirow[t]{5}{*}{ Lap-1 } & A & 0.03 & 0.04 & 0.10 & 0.67 & 0.55 \\
\hline & B & 0.56 & 0.45 & 0.54 & 0.28 & 0.27 \\
\hline & $\mathrm{C}$ & 0.36 & 0.49 & 0.29 & 0.02 & 0 \\
\hline & $\mathrm{D}$ & 0.05 & 0.02 & 0.07 & 0 & 0 \\
\hline & $\mathrm{E}$ & 0 & 0 & 0 & 0.03 & 0.18 \\
\hline \multirow[t]{3}{*}{$M d h-1$} & A & 0.01 & 0 & 0.03 & 0 & 0 \\
\hline & B & 0.01 & 0 & 0.02 & 0 & 0 \\
\hline & $\mathrm{C}$ & 0.98 & 1.00 & 0.95 & 1.00 & 1.00 \\
\hline \multirow[t]{4}{*}{$M d r-1$} & A & 0.16 & 0.01 & 0.13 & 0 & 0 \\
\hline & B & 0.63 & 0.63 & 0.30 & 0.48 & 0.37 \\
\hline & $\mathrm{C}$ & 0.12 & 0.12 & 0.39 & 0.50 & 0.60 \\
\hline & $\mathrm{D}$ & 0.09 & 0.24 & 0.18 & 0.02 & 0.03 \\
\hline \multirow[t]{3}{*}{$6 p g d-1$} & A & 0.47 & 0.48 & 0.28 & 0.05 & 0 \\
\hline & B & 0.51 & 0.47 & 0.66 & 0.35 & 0.66 \\
\hline & C & 0.02 & 0.05 & 0.06 & 0.60 & 0.34 \\
\hline \multirow[t]{3}{*}{ 6pgd-2 } & A & 0.71 & 0.22 & 0.35 & 0 & 0.08 \\
\hline & B & 0.22 & 0.60 & 0.49 & 1.00 & 0.92 \\
\hline & C & 0.07 & 0.18 & 0.16 & 0 & 0 \\
\hline \multirow[t]{4}{*}{ Pgm-1 } & A & 0.03 & 0 & 0.02 & 0 & 0 \\
\hline & B & 0.48 & 0.95 & 0.55 & 0.04 & 0 \\
\hline & $\mathrm{C}$ & 0.29 & 0.05 & 0.37 & 0.94 & 1.00 \\
\hline & D & 0.20 & 0 & 0.06 & 0.02 & 0 \\
\hline \multirow[t]{4}{*}{ Pgm-2 } & A & 0.08 & 0.06 & 0.10 & 0.01 & 0 \\
\hline & B & 0.64 & 0.89 & 0.73 & 0.99 & 1.00 \\
\hline & C & 0.27 & 0.05 & 0.14 & 0 & 0 \\
\hline & $\mathrm{D}$ & 0.01 & 0 & 0.03 & 0 & 0 \\
\hline \multirow[t]{3}{*}{ Pgm-3 } & A & 0.80 & 0.67 & 0.66 & 0.61 & 0.69 \\
\hline & B & 0.20 & 0.33 & 0.34 & 0.35 & 0.31 \\
\hline & $\mathrm{C}$ & 0 & 0 & 0 & 0.04 & 0 \\
\hline
\end{tabular}

between populations $\left(G_{\mathrm{ST}}=0.275\right)$ when compared to many other plant species (Hamrick \& Godt, 1989). If all five populations are considered then genetic diversity appears to be equally partitioned within and among populations. There are, however, two distinct population groups within this species (Fig. 2) and the partitioning of genetic diversity between the populations within each group is noticeably different (Table 4).

In the Wongan Hills area there is noticeable differentiation between the three populations $\left(G_{\mathrm{ST}}=0.153\right.$, $\left.F_{\mathrm{ST}}=0.155\right)$ and the gene flow estimates $(\mathrm{Nm})$ indicate no significant migration between populations separated by just a few kilometres. In contrast, there is little differentiation and significant levels of gene flow estimated between the two Maya populations, which are also separated by only a few kilometres. In fact the level of gene flow estimated between the two Maya populations was marginally higher than the gene flow estimates between the sub populations of population 3 (Table 4).

Differentiation between the two disjunct population groups is very high (Nei's genetic distance, $D=0.29$; Fig. 2) and as might be expected, for an insect-pollinated species with two population groups separated by over one hundred kilometres, the estimate of gene flow between all populations, based on $F_{\mathrm{ST}}$, is extremely low (Table 4). In contrast the estimate based on Slatkin's private allele method (Slatkin, 1985) is unexpectedly high, although this is probably the result of a sampling error based on the distribution of private alleles within these populations.

\section{Spatial autocorrelation}

Spatial autocorrelation analysis provided no evidence for spatial genetic structure in population 1 when sampled six years after the bottleneck. Tests for correlations between nearest neighbours were based on either the Gabriel-connection algorithm or the nearest neighbour algorithm and in each case only 1 out of 14 alleles provided any evidence for spatial genetic structure. These were allele $6 p g 1 b$ for the Gabrielconnected maps and allele $\operatorname{Pgm} 3 b$ for the nearest-neighbour maps (Table 5). Spatial structure was also tested for pairs of individuals within a specified distance class and again no spatial structure was detected for any distance class.

\section{Discussion}

A substantial and prolonged reduction in population size or population bottleneck is commonly expected to result in a loss of genetic diversity, reduced heterozygosity and increased differentiation between popula- 
tions (see Nei et al., 1975; Johnson, 1988), In $S$. coroniforme population 1 was subjected to a prolonged decline in numbers resulting in a bottleneck of probably three plants followed by a rapid recovery to 86 plants 6 years later. The data presented in this study indicate that the genetic consequences of this bottleneck, either in terms of allelic diversity or average heterozygosity, are negligible (Tables 2 and 3 ).

Table 3 Single locus diversity measure for $S$. coroniforme

\begin{tabular}{lclllll}
\hline Population & $N_{\mathrm{L}}$ & $A$ & $P$ & $H_{\mathrm{O}}$ & $H_{\mathrm{e}}$ & $F$ \\
\hline 1 Old (4-9 years) & 16.7 & 2.5 & 86.7 & $0.33(0.07)$ & $0.40(0.06)$ & $0.14(0.06)$ \\
Young(1-4 years) & 58.1 & 2.7 & 86.7 & $0.29(0.05)$ & $0.41(0.06)$ & $0.28(0.04)$ \\
All & 74.8 & 2.9 & 86.7 & $0.30(0.05)$ & $0.41(0.06)$ & $0.25(0.03)$ \\
2 & 41.5 & 2.4 & 80.0 & $0.24(0.06)$ & $0.29(0.06)$ & $0.22(0.05)$ \\
3 Sub population 1 & 19.8 & 2.5 & 86.7 & $0.27(0.04)$ & $0.37(0.05)$ & $0.22(0.06)$ \\
Sub population 2 & 29.3 & 2.8 & 86.7 & $0.29(0.05)$ & $0.41(0.06)$ & $0.24(0.05)$ \\
All & 49.1 & 2.9 & 86.7 & $0.28(0.04)$ & $0.41(0.06)$ & $0.26(0.04)$ \\
4 & 31.5 & 2.5 & 78.6 & $0.21(0.05)$ & $0.32(0.06)$ & $0.28(0.05)$ \\
5 & 16.9 & 2.0 & 66.7 & $0.16(0.05)$ & $0.23(0.06)$ & $0.31(0.09)$ \\
\hline
\end{tabular}

$N_{\mathrm{L}}=$ mean sample size per locus; $A=$ mean number of alleles per locus; $P=$ percentage of polymorphic loci;

$H_{\mathrm{O}}$ observed heterozygosity; $H_{\mathrm{e}}=$ expected panmictic heterozygosity; $F=$ average

fixation index.

Standard errors are in parentheses.

Table 4 Gene diversity measures $F_{\mathrm{ST}}$ and gene flow estimates for the Wongan and Maya populations based on 13 polymorphic allozyme loci

\begin{tabular}{lcccccccc}
\hline & & & & \multicolumn{4}{c}{$\mathrm{Nm}$} \\
Population & $H_{\mathrm{T}}$ & $H_{\mathrm{S}}$ & $G_{\mathrm{ST}}$ & $p(1)$ & $F_{\mathrm{ST}}$ & Slatkin & Wright \\
\hline Wongan & & & & & & & \\
$\begin{array}{l}1,2,3 \\
\text { 3(sub populations 1 and 2) })\end{array}$ & 0.50 & 0.43 & 0.15 & 0 & 0.16 & - & 1.36 \\
Maya & 0.49 & 0.45 & 0.08 & 0.06 & 0.04 & 1.77 & 6.69 \\
4,5 & 0.32 & 0.30 & 0.05 & 0.04 & 0.03 & 2.40 & 8.08 \\
All & 0.52 & 0.38 & 0.28 & 0.04 & 0.25 & 2.11 & 0.75 \\
\hline
\end{tabular}

$H_{\mathrm{T}}=$ total genetic diversity; $H_{\mathrm{S}}=$ genetic diversity within populations;

$G_{\mathrm{ST}}=$ proportion of total genetic diversity among populations; $p(1)=$ frequency of private alleles; $\mathrm{Nm}=$ estimate of gene flow.

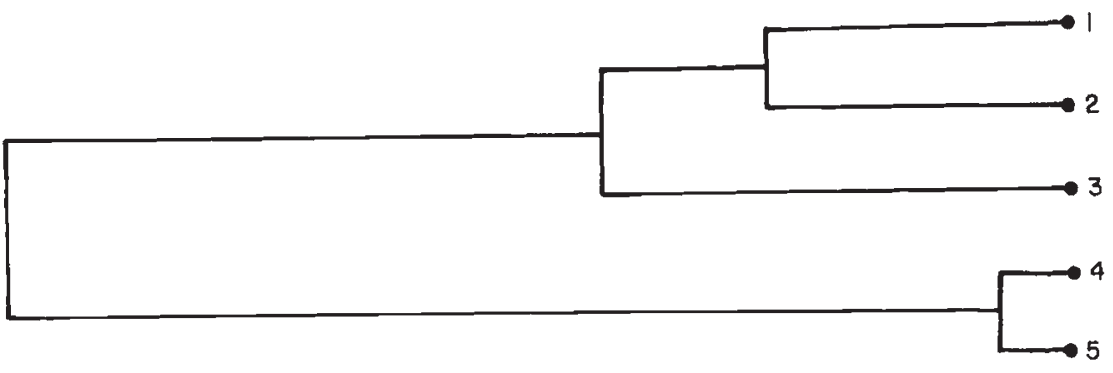

Fig. 2 UPGMA clustering of Stylidium coroniforme populations based on Nei's genetic distance $(\vec{D})$.

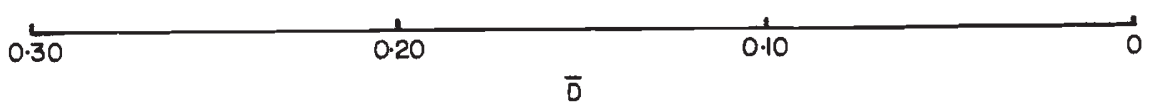


Table 5 Moran's I, a coefficient of spatial autocorrelation based on ranks, its standard deviationn (s.d.) and the probability $(P)$ for the null hypothesis $I=0$ (no spatial structure), based on two methods of pairing individuals in the Wongan 1 population of $S$. coroniforme

\begin{tabular}{|c|c|c|c|c|c|c|}
\hline \multirow[b]{2}{*}{ Allele } & \multicolumn{3}{|c|}{ Gabriel-connected map } & \multicolumn{3}{|c|}{ Nearest-neighbour map } \\
\hline & $I$ & s.d. & $P$ & $I$ & s.d. & $P$ \\
\hline Aat2a & -0.07 & 0.13 & 0.72 & -0.01 & 0.20 & 0.92 \\
\hline Lap Ib & -0.03 & 0.11 & 0.91 & 0.01 & 0.16 & 0.86 \\
\hline Lap 1c & 0.05 & 0.11 & 0.56 & 0.03 & 0.16 & 0.96 \\
\hline Lap Id & -0.01 & 0.11 & 0.92 & -0.03 & 0.16 & 0.88 \\
\hline $6 p g 1 \mathrm{~b}$ & -0.02 & 0.11 & 0.98 & 0.02 & 0.16 & 0.80 \\
\hline $6 p g 2 b$ & -0.26 & 0.11 & $0.03^{*}$ & -0.03 & 0.16 & 0.10 \\
\hline Pgila & -0.02 & 0.10 & 0.97 & 0.08 & 0.16 & 0.55 \\
\hline Pgi2a & -0.09 & 0.11 & 0.50 & -0.12 & 0.16 & 0.51 \\
\hline Pgi2b & 0.05 & 0.11 & 0.56 & -0.03 & 0.16 & 0.96 \\
\hline Pgi2c & 0.13 & 0.11 & 0.17 & 0.12 & 0.16 & 0.40 \\
\hline Pgm 1b & -0.03 & 0.11 & 0.91 & 0.01 & 0.16 & 0.86 \\
\hline Pgm1c & -0.03 & 0.11 & 0.91 & 0.01 & 0.16 & 0.86 \\
\hline Pgm 2b & 0.10 & 0.11 & 0.29 & 0.21 & 0.17 & 0.17 \\
\hline Pgm3b & 0.19 & 0.11 & 0.07 & 0.50 & 0.17 & $0.00^{* *}$ \\
\hline
\end{tabular}

Gabriel-connection algorithm: pairs two individuals, $\mathrm{A}$ and $\mathrm{B}$, if no other individual lies on or within the circle whose diameter is the line AB. Nearest-neighbour algorithim: pairs each individual only with the nearest sampled plant.

${ }^{*} P<0.05,{ }^{* *} P<0.01$.

Before the bottleneck, population 1 had been subjected to a period of prolonged habitat disturbance and grazing, after which population recovery was relatively rapid (see Table 1). This rapid recovery rate may account for the negligible effect on average heterozygosity as predicted in theoretical models by Nei et al. (1975) and Chakrabroty \& Nei (1977). However, given the influence of other factors, such as the breeding system and selection, population recovery rate is unlikely to be the only reason for the maintenance of heterozygosity in this population.

S. coroniforme, like other triggerplants, has a pollination system which promotes cross pollination although it is self compatible and geitonogamy, resulting in self pollination, is likely to be common in natural populations (S. H. James personal communication). Self pollination, however, results in significantly higher levels of postzygotic seed abortion than cross pollination. There is strong evidence to suggest that postzygotic seed abortion in Stylidium is due to a high frequency of recessive lethal genes (James, 1979; Burbridge \& James, 1991). In many plant species, including triggerplants (Banyard \& James, 1979), decreased seed yields are also found following crossing between near neighbours, which are often closely related (Price \& Waser, 1979; Levin, 1984). This reduction in seed viability is also considered to be due to the expression of largely recessive deleterious genes in homozygotes (see Lande \& Schemske, 1985). The progressive elimination of selfed or otherwise inbred products from a developing seed cohort will result in an increase in the proportion of heterozygotes. One likely consequence of this breeding system would therefore be the maintenance of relatively high levels of heterozygosity in small populations.

Selection against inbred individuals beyond the embryo stage mentioned above, through the seedling stage to the mature plant has also been demonstrated in some plant species (Ledig, 1986; Plessas \& Strauss, 1986). This results in a decrease in $F$ towards zero during the lifecycle of the plant, a trend apparent in population 1 of $S$. coroniforme. Excesses of heterozygotes $(F<1)$ indicating selection favouring heterozygotes or overdominance have also been demonstrated in some cases (see Mitton 1989). Both these effects may reduce the impact of small population size on heterozygosity and, as a consequence, allelic diversity. In the case of $S$. coroniforme selection against inbred individuals, either through the action of deleterious recessive genes or against selfed genotypes, appears to be likely. If so, it will clearly be an important factor in maintaining heterozygosity within populations regardless of population size or, within limitations, severity of a bottleneck.

Recently Mopper et al. (1991) found evidence to suggest that heterozygosity of specific loci may increase resistance to herbivory and environmental stress in Pinus edulis. This supports the general patterns observed within other plant species, where the increase in average heterozygosity is associated with increased fitness (Mitton, 1989). Prior to fencing, population 1 was subjected to intense and prolonged stress due to grazing and habitat disturbance. It is possible that in $S$. coroniforme there is an association between grazing and/or habitat disturbance and increased average heterozygosity. Thus, plants which survived the bottleneck may have been highly heterozygous in comparison to the average plant found in the original population. This association is currently under investigation.

Although a bottleneck followed by a rapid increase in population size or 'flush' may not necessarily lead to reduced average heterozygosity or reduced allelic diversity in a species such as $S$. coroniforme, it is likely to result in rapid and significant differentiation between populations (see Taggert et al., 1990). One might therefore expect greater differentiation between population 1 , and populations 2 and 3 , than between the geographically closer and apparently more stable populations 2 and 3 . Interestingly this was not the case: 
population 2 was well separated from populations 1 and 3 (Fig. 2). The relatively high level of differentiation between the Wongan populations may be the result of repeated bottleneck-flush cycles in all three populations. The bottleneck observed in population 1 could then be considered typical of these populations rather than a single anomalous event.

In contrast with the Wongan populations, there is a much lower level of divergence between the Maya populations. The average $F_{\mathrm{ST}}$ (Table 4) for the Wongan populations is some five times greater than that for Maya populations, yet in both cases populations are separated by only a few kilometres. Although these data may be indicative of a founder events within the Wongan populations only, it is also possible that other factors are influencing the patterns of divergence within the two population groups. Given the level of divergence between the Wongan and Maya populations (Fig. 2) we may be dealing with different species. Increased gene flow and reduced divergence between populations in only one species may be associated with species-specific differences in pollinator behaviour. Recent observations suggest that there may be different pollinators operating within the two population groups.

Proposals that population bottlenecks may be the trigger for rapid and recent speciation (Carson \& Templeton, 1984) seem to be relevant to the findings in this study. Bottleneck-flush cycles, which are probably characteristic of $S$. coroniforme populations, also appear to be a feature of populations of many other perennial triggerplants. They are no doubt a significant factor in the explosive and apparently recent speciation observed in this genus in the south-west of Australia (James, 1979; Coates, 1981).

Observations that many triggerplants undergo population flushes following a perturbation such as fire also have implications for the genetic structure within populations. This cyclical behaviour will initially result in increased plant density and probably significant population structuring. Over time, however, as competition with other species becomes more intense, plant density will decrease and we would expect any population genetic structure to disappear. This relationship between demographic patterns and spatial genetic structure within populations has been mentioned recently by both Hamrick (1989) and Perry \& Knowles (1991). There was some evidence for this in a recent study of another triggerplant $(\mathrm{S}$. H. James personal communication). In $S$. coroniforme, however, there was no evidence for any spatial genetic structure in population 1 when sampled at its maximum density in 1986 (Table 5).

Although more detailed studies are clearly warranted, particularly of the relationship between heterozygosity and fitness, and whether the two population groups represent different species, it does appear that a temporary reduction in population size is likely to be of little consequence in terms of allelic diversity or heterozygosity in $S$. coroniforme populations. Maintenance of high levels of genetic diversity in small populations appears to be part of the genetic system found in $S$. coroniforme and other triggerplants $(\mathrm{S}$. H. James personal communication). Furthermore, it seems to be typical of perennial species in this genus, which are relatively short lived, disturbance-adapted and have population systems which undergo frequent bottleneck-flush cycles.

\section{Acknowledgements}

I would like to thank Dr Steven Hopper, Dr Sid James and an anonymous referee for their comments on the manuscript and Ron Sokolowski for his excellent technical assistance.

\section{References}

BANYARD, B. J. AND JAMES, S. H. 1979. Biosystematic studies in the Stylidium crassifolium species complex (Stylidiaceae). Aust. J. Bot., 27, 27-37.

BRowN, A. H. D. 1979. Enzyme polymorphisms in plant populations. Theor. Pop. Biol., 15, 1-42.

BROWN, A. H. D. 1989. Genetic characterization of plant mating systems. In: Brown, A. H. D., Clegg, M. T., Kahler, A. L. and Weir, B. S. (eds) Plant Population Genetics, Breeding and Genetic Resources, Sinauer Associates, Sunderland, MA, pp. 145-162.

BROWN, A. H. D. AND BURDON, J. J. 1983. Multilocus diversity in an outbreeding weed, Echium plantagineum L. Aust. J. Biol. Sci., 36, 503-509.

BROWN, A. H. D. AND WEIR, B. A. 1983. Measuring genetic variability in plant populations. In: Tanksley, S. D. and Orton, T. J. (eds) Isozymes in Plant Genetics and Breeding, Elsevier, Amsterdam, pp. 219-239.

BURBIDGE, A. H. AND JAMES, S. H. 1991. Postzygotic seed abortion in the genetic system of Stylidium (Angiospermae: Stylidiaceae). J. Hered., 82, 319-328.

CARSON, H. L. AND TEMPLETON, A. R. 1984. Genetic revolutions in relation to speciation phenomena: the founding of new populations. Ann. Rev. Ecol. Syst., 15, 97-131.

COATES, D. J. 1981. Chromosome, morphometric and breeding system studies in the Stylidium caricifolium species complex (Stylidaceae). Aust. J. Bot., 27, 397-417.

COATES, D. J. 1988. Genetic diversity and population genetic structure in the rare Chittering grass wattle Acacia anomala (Court) Aust. J. Bot., 36, 273-286.

CHAKRABORTY, R. AND NEI, M. 1977. Bottleneck effects on average heterozygosity and genetic distance with the stepwise mutation model. Evolution, 31, 347-356. 
DEWEY, S. E. AND HEYWOOD, J. S. 1988. Spatial genetic structure in a population of Psychotria nervosa. I. Distribution of genotypes. Evolution, 42, 834-838.

ERICKSON, R. AND WILLIS, J. H. 1966. Some additions to Australian Stylidiaceae. Vic. Nat., 73, 43-44.

HAMRICK, J. L. 1989. Isozymes and the analysis of genetic structure in plant populations. In: Soltis, D. E. and Soltis, P. S. (eds) Isozymes in Plant Biology, Dioscorides Press, Portland, pp. 73-86.

HAMRICK, J. L. AND GODT, M. J. 1989. Allozyme diversity in plant species. In: Brown, A. H. D., Clegg. M. T., Kahler, A. L. and Weir, B. S. (eds) Plant Population Genetics, Breeding, and Genetic Resources, Sinauer Associates, Sunderland, MA, pp. 43-63.

HOPPER, S. D. 1982. Hand pollination of rare triggerplant successful. Swans, 12, 12-15.

JAMES, S. H. 1979. Chromosome numbers and genetic systems in the triggerplants of Western Australia. Aust. J. Bot., 27, $17-25$.

JOHNSON, M. S. 1988. Founder effects and geographic variation in the land snail Theba pisana. Heredity, 61, 133-142.

LANDE, R. AND SCHEMSKE, D. W. 1985. The evolution of selffertilization and inbreeding. 1. Genetic Models. Evolution, 39, 24-40.

LEDIG, F. T. 1986. Heterozygosity, heterosis, and fitness in outbreeding plants. In: Soule, M. E. (ed.) Conservation Biology, the Science of Scarcity and Diversity, Sinauer Associates, Sunderland, MA, pp. 77-104.

LEVIN, D. A. 1984. Inbreeding depression and proximitydependent crossing success in Phlox drummondii. Evolution, 38, 116-127.

MCLENAGHAN, L. R. AND BEAUCHAMP, A. C. 1986. Low genic differentiation among isolated populations of the California fan palm (Washingtonia filifera). Evolution, 42, 315-322.

MITTON, J. B. 1989. Physiological and demographic variation associated with allozyme variation. In: Soltis, D. E. and Soltis, P. S. (eds) Isozymes in Plant Biology, Dioscorides Press, Portland, pp. 127-145.

MOPPER, S., MITTON, J. B., WHITHAM, T. G., COBB, N. S. AND CHRISTENSEN, K. M. 1991. Genetic differentiation and heterozygosity in pinyon pine associated with resistance to herbivory and environmental stress. Evolution, 45, 989-999.

MORAN, G. F. AND HOPPER, S. D. 1983. Genetic diversity and insular population structure of the rare granite rock species Eucalyptus caesia Benth. Aust. J. Bot., 31, 161-172.

MORAN, G. F. AND HOPPER, S. D. 1987. Conservation of the genetic resources in of rare and widespread eucalypts in remnant vegetation. In: Saunders, D. A., Arnold, G. W., Burbidge, A. A. and Hopkins, A. J. M. (eds) The Role of Remnants of Native Vegetation, Surrey Beatty, Sydney, pp. 151-162.

NEI, M. 1978. Estimation of average heterozygosity and genetic distance from a small number of individuals. Genetics, 89, 583-590.

NEI, M. AND CHESSER, R. K. 1983. Estimation of fixation indices and gene diversities. Ann. Hum. Genet., 47, 253-259.

NEI, M., MARUYAMA, T. AND CHAKRABROTY, R. 1975. The bottleneck effect and genetic variability in populations. Evolution, 29, 1-10.

PERRY, D. J. AND KNOWLES, P. 1990. Spatial genetic structure within sugar maple (Acer saccharum Marsh) stands. Heredity, 66, 137-142.

PLESSAS, M. E. AND STRAUSS, S. H. 1986. Allozyme diffentiation among populations, stands, and cohorts in Monterey pine. Can. J. For. Res., 16, 1155-1164.

PRICE, M. V. AND WASER, N. N. 1979. Pollen dispersal and optimal outcrossing in Delphinium nelsonii. Nature, 277, 294297.

RITLAND, K. 1986. Joint maximum likelihood estimation of genetic and mating structure using open pollinated progenies. Biometrics, 42, 25-43.

RYE, B. L. 1980. Rare and geographically restricted plants of Western Australia. 4. Wongan Hills species. Unpublished report, Department of Fisheries and Wildlife, Perth.

SCHAAL, B. A. 1980. Measurement of gene flow in Lupinus texensis. Nature, 284, 450-451.

SCHWAEGERLE, K. E. AND SCHAAL, B. A. 1979. Genetic variability and founder effect in the pitcher plant Sarracenia purpurea L. Evolution, 33, 1210-1218.

SLATKIN, M. 1985. Rare alleles as indicators of gene flow. Evolution, 39, 53-65.

SLATKIN, M. AND BARTON, N. H. 1989. A comparison of three indirect methods for estimating average levels of gene flow. Evolution, 43, 1349-1368.

SOKAL, R. R. AND ODEN, N. L. 1978. Spatial autocorrelation in biology. 1. Methodology. Biol. J. Linn. Soc., 10, 199-228.

SWOFFORD, D. L. AND SELANDER, R. K. 1981. A computer program for the analysis of allelic variation in genetics. $J$. Hered., 72, 281-283.

TAGGERT, J. B., MCNALLY, S. F. AND SHARP, P. M. 1989. Genetic variability and differentiation among founder populations of the pitcher plant (Sarracenia purpurea) in Ireland Heredity, 64, 177-183.

WASER, N. M. 1987. Spatial genetic heterogeneity in a population of the montane perennial plant. Delphinium nelsonii. Heredity, 58, 249-256.

WATKINS, L. AND LEVIN, D. A. 1990 . Outcrossing rates as related to plant density in Phlox drummondii. Heredity, 65 , 81-90.

WEIR, B. S. AND COCHRAN, C. c. 1984 . Estimating $F$ statistics for the analysis of population structure. Evolution, 38 , 1358-1370.

WHITE, M. J. D. 1978. Modes of Speciation. Freeman, San Francisco.

WRIGHT, s. 1951. The genetical structure of populations. Ann. Eugen., 15, 323-354. 